\title{
Cytomegalovirus and inflammatory bowel disease
}

\author{
R. Morton \\ Department of Pathology, Southern General Hospital, Glasgow G51 4TF, UK.
}

\begin{abstract}
Summary: An 80 year old man was admitted to hospital with a 4 month history of diarrhoea with blood and mucus. The diarrhoea could not be controlled by a variety of drugs and he died 7 weeks later. Rectal biopsy showed both intranuclear and intracytoplasmic inclusional bodies consistent with cytomegalovirus infection.
\end{abstract}

\section{Introduction}

Cytomegalovirus (CMV) is the commonest cause of intra-uterine infection and may present particular problems in the neonatal period resulting in a variety of defects including neonatal retardation, deafness and chorioretinitis. In the adult immuno-suppressed individuals are particularly susceptible to infection and interest has arisen recently, as a result of the association of CMV with a variety of gastro-intestinal lesions and with the acquired immune deficiency syndrome. In this latter group it has been suggested that CMV may be aetiologically associated with the development of Kaposi's sarcoma (Levy \& Ziegler, 1983). This case concerns CMV infection associated with an extremely severe form of colitis and raises the possibility that some cases of colitis may be CMVinduced.

\section{Case report}

An 80 year old man was admitted to hospital as an emergency with a 4 month history of diarrhoea accompanied by blood and mucus having lost $1 \frac{1}{2}$ stones in weight. On admission he was having episodes of diarrhoea approximately every $\frac{1}{2}$ hour and was pyrexial with a temperature of $38.2^{\circ} \mathrm{C}$. He was found to be anaemic and normotensive. A mid-line infraumbilical hernia and left sided hydrocele were noted.

Investigations showed haemoglobin $9.2 \mathrm{~g} / 1$, erythrocyte sedimentation rate $45 \mathrm{~mm} / \mathrm{h}$. Sternal marrow examination showed megaloblastic erythropoiesis and this was related to both low serum vitamin $B_{12}(78 \mathrm{ng} / 1)$ and red cell folate $(75 \mu \mathrm{g} / \mathrm{l})$ levels for no apparent cause. Stool cultures were unremarkable. Sigmoidoscopy showed several discrete, large shallow ulcers surrounded by a hyperaemic and oedematous mucosa.

Correspondence: R. Morton, M.B., Ch.B., M.R.C.Path. Accepted: 21 June 1985
Barium enema examination showed a grossly irregular and ulcerated mucosa involving rectum and lower sigmoid colon.

Treatment consisted of large doses of corticosteroids, tetracycline, metronidazole and cholestyramine, but despite this combined therapy the diarrhoea persisted and was extremely profuse.

Five weeks following admission, rectal biopsies were performed. Histological examination showed severe active inflammatory bowel disease but of particular interest was the presence of both intranuclear (owl's eye) and intracytoplasmic inclusion bodies within endothelial cells and histiocytes (Figure 1). These features are regarded as diagnostic of CMV infection. The CMV inclusions were confined to those areas of active disease and were absent from microscopically normal mucosa. Rectal mucosal tissue was also submitted for electron microscopical examination which demonstrated the presence of viral particles

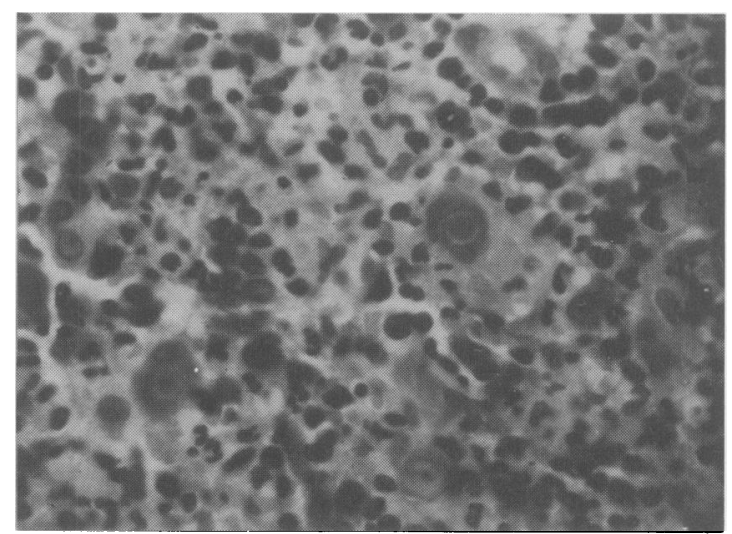

Figure 1 Granulation tissue with intranuclear 'owl's eye' inclusion bodies. H \& E $\times 400$.

(C) The Fellowship of Postgraduate Medicine, 1985 
(Figure 2). Subsequent serological examinations showed CMV complement fixation titres of 1:128 and 1:256. IgM antibodies to CMV were absent. The patient continued to have intractable diarrhoea such that a total colectomy was contemplated. However, he developed a severe respiratory infection and died approximately 7 weeks following admission.

At autopsy there were numerous $0.5-1 \mathrm{~cm}$ diameter 'punched-out' ulcers in the mucosa of the rectum and extending over a distance of $20 \mathrm{~cm}$ from the anal margin (Figure 3). Some of the ulcers were arranged in a linear, longitudinal fashion. The overall mucosal appearances were unlike those seen in typical ulcerative colitis or Crohn's disease.

Histological examination showed the presence of numerous CMV inclusions within endothelial, histiocytic and fibroblastic cells and confined to those areas of ulceration. Occasional thrombotic occlusions of some of the small, virally infected capillaries in relation to those areas of ulceration were also noted. Viral inclusions were not identified in salivary tissue, kidney, liver or pancreas but were very occasionally seen in pulmonary alveolar lining cells.

\section{Discussion}

Cytomegalovirus has been associated with diverse gastro-intestinal lesions including gastric and duodenal ulceration (Campbell et al., 1977; Henson, 1972) and ulcerative colitis (Cooper et al., 1977; Farmer et al., 1973; Foucar et al., 1981; Powell et al., 1960; Sidi et al., 1979; Tamura, 1973; Wong \& Warner, 1962).

Foucar et al. (1981) reported 6 renal transplant patients who developed CMV infection associated with severe colonic bleeding and mucosal ulceration. Despite colectomy in four patients, all six died within 84 days of the onset of symptoms. There was histological evidence of a CMV vasculitis in all 6 cases and it was suggested that the colonic mucosal damage was a direct result of this vasculitis. A similar vasculitic pathology was noted in the case of fatal colonic haemorrhage reported by Goodman \& Porter (1973).

Foucar et al. (1981) also found that the spectrum of colonic mucosal changes in 12 non-transplant patients, 5 of whom died of colonic haemorrhage, was similar to that of the transplant cases. These changes ranged from small focal superficial ulceration, confined to the proximal right colon, to total colonic ulceration.

There have also been several case reports which suggest that CMV may be implicated in the development of toxic dilatation of the colon in ulcerative colitis (Henson, 1972; Cooper et al., 1977; Swarbrick et al., 1979). Farmer et al. (1973) found that CMV antibody titres greater than 1:8 are more common in ulcerative colitis than in the normal population or in

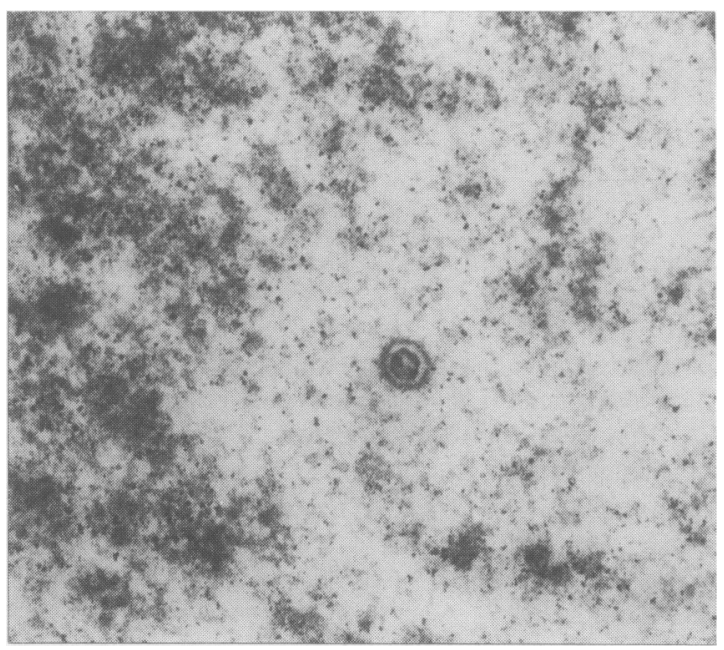

Figure 2 Intracytoplasmic viral particles characterized by a small electron-dense core and single peripheral membrane or capsid. $\times 116,666$.

patients with Crohn's disease.

CMV-induced colitis is an entity, I believe, as in many cases there is no previous history of bowet disease and, of more importance, because of the rathey curious 'punched out' appearance of the colonie ulcers. Similar appearances noted in a case reported by Tamura (1973) were typical of neither ulcerative colitis nor Crohn's disease.

Further evidence in support of an aetiological role played by the virus is the confinement of the virally infected cells to the granulation tissue related to areas of ulceration and the occasional development of a CMV vasculitis with thrombotic occlusion of small blood vessels (Goodman \& Porter, 1973).

Whatever the role, if any, of CMV infection in the pathogenesis of ulcerative intestinal disease, it is



Figure 3 'Punched out' rectal ulcers. 
clearly evident that the prognosis of patients with CMV-associated colitis is particularly poor and that the majority eventually become resistant to antibiotic and/or steroid therapy and may require a total colectomy as a life saving measure (Goodman \& Porter, 1973; Foucar et al., 1981).

Of note is the close association of CMV-associated colitis and steroid therapy, given during the course of treatment for various malignancies, in particular leukaemia and lymphoma (Wong \& Warner, 1962), and as immunosuppressive therapy for transplant patients (Foucar et al., 1981). It is possible that the steroids are responsible for reactivation of latent CMV but in these reports, no attempt appears to have been made to distinguish between primary and reactivated CMV infection. In the present case IgM antibodies were not detected, in keeping with reactivation of latent virus rather than primary infection.

This case report illustrates the importance of iden-

\section{References}

CAMPBELL, D.A., PIERCY, J.R.A., SHNITKA, T.K., GOLDSAND, G., DEVINE, R.D.O. \& WEINSTEIN, W.M. (1977). Cytomegalovirus-associated gastric ulcer. Gastroenterology, 72, 533.

COOPER, H.S., RAFFENSPERGER, E.C., JONAS, L. \& FITTS, W.T. (1977). Cytomeglovirus inclusions in patients with ulcerative colitis and toxic dilatation requiring colonic resection. Gastroenterology, 72, 1253.

FARMER, G.W., VINCENT, M.V., FUCCILLO, D.A., HORTABARBOSA, L., RITMAN, S., SEVER, J.L. \& GITNICK, G.L. (1973). Viral investgations in ulcerative colitis and regional enteritis. Gastroenterology, 65, 8.

FOUCAR, E., MUKAI, K., FOUCAR, K., SUTHERLAND, D.E.R. \& VAN BUREN, C.T. (1981). Colon ulceration in lethal cytomegalovirus infection. American Journal of Clinical Pathology, 76, 788.

GOODMAN, M.D. \& PORTER, D.D. (1973): Cytomegalovirus vasculitis with fatal colonic haemorrhage. Archives of Pathology, 96, 281.

HENSON, D. (1972). C.M.V. inclusion bodies in the gastrointestinal tract. Archives of Pathology, 93, 477.

LEVY, J.A. \& ZIEGLER, J.L. (1983). Acquired immuno- tifying the characteristic inclusions of CMV in rectal biopsies from patients with suspected inflammatory bowel disease as their presence significantly worsens the prognosis and may therefore influence subsequent medical or surgical management. In addition, the sudden development of intractable diarrhoea in patients who are receiving steroid therapy either for inflammatory bowel disease or for any other condition, should alert one to the possibility of CMVassociated or possibly CMV-induced colitis.

\section{Acknowledgements}

I wish to thank Professor R.M. MacSween, Pathology Department, Western Infirmary, Glasgow, and Dr G.P. Crean, Gastro-Intestinal Unit, Southern General Hospital, Glasgow, for valuable advice. My thanks also to Miss $\mathbf{M}$. Dale for typing the manuscript.

deficiency syndrome is an opportunistic infection and Kaposi's sarcoma results from secondary immune stimulation. Lancet, ii, 78.

POWELL, R.D., WARNER, N.E., LEVINE, R.S. \& KIRSNER, J.B. (1960). Cytomegalovirus inclusion disease and ulcerative colitis: Report of a case in a young adult. American Journal of Medicine, 30, 334.

SIDI, S., GRAHAM, J.R. \& RAZVI, S.A. (1979). Cytomegalovirus infection of the colon associated with ulcerative colitis. Archives of Surgery, 114, 857.

STARR, S.E. (1979). Cytomegalovirus. Pediatric Clinics of North America, 21, 283.

SWARBRICK, E.T., KINGHAM, J.G.C., PRICE, H.L., BLACKSHAW, A.S. \& GRIFFITHS, P.D. (1979). Chlamydia, Cytomegalovirus and Yersinia in inflammatory bowel disease. Lancet, ii, 11.

TAMURA, H. (1973): Acute ulcerative colitis associated with cytomegalovirus inclusion virus. Archives of Pathology, 96, 164.

WONG, T.W. \& WARNER, N.E. (1962). Cytomegalic inclusion disease in adults. Report of 14 cases with review of literature. Archives of Pathology, 74, 403. 